\title{
Lycium barbarum polysaccharides exert an antioxidative effect on rat chondrocytes by activating the nuclear factor (erythroid-derived 2)-like 2 signaling pathway
}

Yu Chen ${ }^{1}$, Qing Bi ${ }^{1}$, Ziguan Zhu ${ }^{2}$, Shuijun Zhang ${ }^{1}$, Jifeng $X^{1}{ }^{1}$, Xiaofan Dou ${ }^{1}$, Weihuan Mao ${ }^{3}$

\author{
'Department of Orthopedics, Zhejiang Provincial People's Hospital, People's Hospital \\ of Hangzhou Medical College, Hangzhou, China \\ ${ }^{2}$ Department of Hand Surgery and Reconstruction Surgery, Zhejiang Provincial \\ People's Hospital, People's Hospital of Hangzhou Medical College, Hangzhou, China \\ ${ }^{3}$ Department of Orthopedics, The Fifth People's Hospital of Yuhang District, Hangzhou, \\ China
}

Submitted: 23 May 2017

Accepted: 28 August 2017

Arch Med Sci 2020; 16 (4): 964-973

DOI: https://doi.org/10.5114/aoms.2018.77036

Copyright @ 2018 Termedia \& Banach

\section{Abstract}

Introduction: Oxidative stress is the main cause of osteoarthritis (OA). Lycium barbarum polysaccharides (LBP) have antioxidant properties. Thus, the potential effect of LBP on $\mathrm{H}_{2} \mathrm{O}_{2}$-stimulated chondrocytes was examined.

Material and methods: The cell viability was detected by CCK-8. The reactive oxygen species (ROS) production and apoptosis rates were determined by flow cytometric analysis. The DNA damage was detected by comet assay. Real-time polymerase chain reaction (qPCR) and Western blot assays were performed to examine the expression of histone $2 \mathrm{~A}$ family member $X(\gamma \mathrm{H} 2 \mathrm{AX})$, checkpoint kinase 1 (Chk1), poly ADP-ribose polymerase (PARP), cysteinyl aspartate specific proteinase (caspase)-3/8/9, and nuclear factor (erythroid-derived 2)-like 2 (Nrf2) and its antioxidant-response element (ARE) dependent factors including heme oxygenase-1 (HO-1) and quinine oxidoreductase-1 (NQO-1).

Results: Compared to the $\mathrm{H}_{2} \mathrm{O}_{2}$ group, LBP inhibited the ROS production and DNA damage caused by $\mathrm{H}_{2} \mathrm{O}_{2}(p<0.05)$, respectively. LBP inhibited the mRNA and protein expressions of $\gamma \mathrm{H} 2 \mathrm{AX}$ and Chk $1(p<0.05)$. Meanwhile, LBP significantly decreased apoptosis $(p<0.05)$. And LBP inhibited the expression levels of PARP and Caspase-3/8/9 $(p<0.05)$. Moreover, LBP increased the expression of Nrf2, HO-1 and NQO-1 $(p<0.05)$. Furthermore, the depletion of Nrf2 that mediated by RNA interference reversed the apoptosis and DNA damage inhibition effect of LBP $(p<0.05)$.

Conclusions: LBP protected chondrocytes through inhibiting DNA damage and apoptosis caused by $\mathrm{H}_{2} \mathrm{O}_{2}$, in which the Nrf2/ARE signaling pathway played a positive role. It provided an inspiration for clinical application developing LBP as a therapeutic agent and Nrf2 as a promising candidate.

Key words: Lycium barbarum polysaccharides, antioxidant, nuclear factor (erythroid-derived 2)-like 2 (Nrf2), osteoarthritis.

\section{Introduction}

Osteoarthritis (OA), a multifactorial disease, is the most common chronic disorder with increasing prevalence due to the population aging of modern society. Osteoarthritis is often accompanied by inflammation, stiffness and loss of mobility, with common occurrence in hands,

\author{
Corresponding author: \\ Weihuan Mao \\ Department \\ of Orthopedics \\ The Fifth People's \\ Hospital of \\ 60 Healthcare Road \\ Linping St \\ Yuhang District \\ Hangzhou City \\ Zhejiang Province \\ 311100 Hangzhou \\ China \\ Phone: +86057186222034 \\ E-mail: \\ weihuanmaok@163.com
}


knees, hips and spine. Progressive destruction of articular cartilage is one of the main causes of $\mathrm{OA}$ [1], which might be caused by oxidative stress $[2,3]$, pro-inflammatory cytokines [4], mitochondrial dysfunction [5] and endoplasmic reticulum (ER) stress [6, 7]. It is reported that sex and age are related to $O A[8,9]$.

The conservative treatment used to control pain accompanying $\mathrm{OA}$ is the administration of non-steroidal anti-inflammatory drugs (NSAIDs). However, gastrointestinal problems are very common after the use of NSAIDs [10, 11]. In addition, the patients need to undergo costly surgical intervention [12]. To find and develop safe, effective, low cost and locally available drugs will bring benefit to the public. Lycium barbarum polysaccharides (LBP) are the main active components in L. barbarum, whose berries, red in color and sweet in taste, have been used as a traditional herb and food in China for more than 2500 years [13]. Lycium barbarum polysaccharides are mainly composed of arabinose, glucose, galactose, mannose, xylose and rhamnose [14]. The compounds have been stated to hold a wide array of activities [15], including antioxidant and anti-ageing $[16,17]$, and anticancer $[18,19]$. Their protective effects on the reproductive system [20], nervous system [21] and immune system [22] have already been demonstrated. However, the protective effect of LBP on chondrocytes has not yet been examined in detail and the underlying mechanisms are still indistinct. It is reported that reactive oxygen species (ROS) acted as signaling intermediates of intracellular signaling that participate in cartilage homeostasis maintenance [23, 24]. Excessive ROS exposure would lead to disruption of cartilage homeostasis $[25,26]$. Nuclear factor (erythroid-derived 2)-like 2 ( $\mathrm{Nrf2}$ ), is a redox sensitive transcription factor. It is claimed that activation of Nrf2 signaling protected against oxidative stress and various forms of inflammation [25, 27]. Nrf2 regulates the expression of heme oxygenase-1 (HO-1) and quinine oxidoreductase-1 (NQO-1) through antioxidant-response elements (AREs) [28]. A recent study showed that Nrf2-knockout mice exhibited more severe cartilage damage than wild-type mice [29]. Based on these findings, we speculated that LBP may protect chondrocytes against OA through the Nrf2/ARE signaling pathway. Therefore, the current study was aimed to explore this hypothesis in vitro.

\section{Material and methods}

\section{Cell lines and LBP preparation}

Rat chondrocytes were purchased from American Type Culture Collection (ATCC, USA). Purified LBP (95\% Ultra violet Pure) were purchased from
Xian Runxue Biological Technology Co., LTD (Runxue, China), the origin of which is Ningxia wolfberry dried fruit.

\section{Cell treatment}

Chondrocytes $\left(1 \times 10^{5} /\right.$ well) were seeded in a 6-well plate at $37^{\circ} \mathrm{C}$ in a humidified $5 \% \mathrm{CO}_{2}$ atmosphere in Dulbecco's Modified Eagle Media (DMEM) (Invitrogen, USA) supplemented with 10\% fetal bovine serum (FBS) (Sangon, China) and 1\% pen/strep (Sangon, China). At about 80\% confluence, chondrocytes were serum starved overnight and then four treatment groups were used for comparison: 1) normal group, chondrocytes were cultured with $0.1 \%$ DMSO; 2) model group, chondrocytes were treated with $0.3 \mathrm{~mm} \mathrm{H}_{2} \mathrm{O}_{2}$; 3$) 0.2 \mathrm{mg} / \mathrm{ml}$ LBP treatment groups, chondrocytes were incubated in the medium containing $0.2 \mathrm{mg} / \mathrm{ml}$ LBP for $12 \mathrm{~h}$ before $\mathrm{H}_{2} \mathrm{O}_{2}$ stimulation for $6 \mathrm{~h}$. 4) $0.4 \mathrm{mg} / \mathrm{ml} \mathrm{LBP}$ treatment groups, chondrocytes were incubated in the medium containing $0.4 \mathrm{mg} / \mathrm{ml}$ LBP for $12 \mathrm{~h}$ before $\mathrm{H}_{2} \mathrm{O}_{2}$ stimulation for $6 \mathrm{~h}$. All the experiments for each group were repeated independently at least 3 times.

\section{Cell transfection with siRNA}

At about $80 \%$ confluence, cells were transfected with $100 \mathrm{nM}$ siRNA-Nrf2 (SMARTpool) or SiRNA Universal Negative Controls (Sigma-Aldrich, USA) using Lipofectamine 2000 (Invitrogen, USA). After $36 \mathrm{~h}$, the cells were treated with LBP before $\mathrm{H}_{2} \mathrm{O}_{2}$ stimulation in serum free medium. Western blot was performed to detect the effects of siRNA on Nrf2 expression. Sequence of siRNA-Nrf2 Forward: UCCCGUUUGUAGAUGACAA; Reverse: UUGUCAUCUACAAACGGGA.

\section{Cell viability assay}

Chondrocytes of a 96-well plate $\left(1 \times 10^{5}\right.$ cells/ well) were serum starved overnight, and then treated with $\mathrm{H}_{2} \mathrm{O}_{2}(0.1-0.5 \mu \mathrm{M})$ in serum free medium for different time periods (6, 12, 24 and $48 \mathrm{~h}$ ). Cell viability was determined using the CKK- 8 kit according to the instructions (Beyotime, China). The absorption at $450 \mathrm{~nm}$ was measured by microplate reader (Bio-Rad, USA).

\section{Reactive oxygen species (ROS) measurement}

Cells were stained with 2',7'-dichlorodihydrofluorescein diacetate (DCHF-DA) (Invitrogen, USA) for ROS measurement as described previously [30]. Becton Dickinson (BD) Fluorescence Activating Cell Sorter (FACS) Canto II was used to perform flow cytometric analysis. All are representatives of at least three independent experiments. At least 20,000 events were analyzed. 


\section{Measurement of apoptosis}

Chondrocytes $\left(1 \times 10^{5} /\right.$ well $)$ were cultured in 6-well plates. The Annexin V/PI apoptosis kit (Invitrogen, USA) was adopted to detect the apoptosis. As described in the manufacturer's instructions, the Annexin- $\mathrm{V}$ and PI binding was analyzed using fluorescence-activated cell sorting (BD Canto II, USA).

\section{Total RNA isolation and real time PCR}

Total RNA was isolated using RNAiso reagent (Takara, Japan). In brief, the collected cells were lysed with RNAiso Plus, and maintained at room temprature for $5 \mathrm{~min}$. After being centrifuged at $12,000 \mathrm{~g}$ at $4^{\circ} \mathrm{C}$ for $5 \mathrm{~min}$, the supernatant was removed out and mixed with chloroform (Sinopharm Chemical Regent Co., Ltd, China). After mixing with isopropyl alcohol (SCRC, China) followed by centrifuging, the RNA precipitate was washed with $70 \%$ ethanol 3 times. Then the RNA precipitate was dissolved in RNase-free water. Subsequently, according to the manufacturer's instructions, the cDNA was synthesized using ReverTra Ace (Toyobo, Japan), RNA (1 $\mu \mathrm{g})$ and oligo dT (Takara, Japan). The mRNA expression was quantified with SYBR Green PCR master mix (Applied Biosystems, USA) and $A B I 7500$ Real-time PCR system (Applied Biosystems, USA). Relative expression levels were calculated using the $2^{-\Delta \Delta C T}$ method [31]. Primer sequences for real-time PCR were as below:

Nrf2 forward: CTGCCATTAGTCAGTCGCTCTC; Nrf2 reverse: TCAGTGTGCTTCTGGTTGAAAG; NQO-1 forward: TTTAGGGTCGTCTTGGCA; NQO-1 reverse: GTCTTCTCTGAATGGGCCAG; HO-1 forward: ACATCGACAGCCCCACCAAGTTCAA; HO-1 reverse: CTGACGAAGTGACGCCATCTGTGAG; $\gamma \mathrm{H} 2 \mathrm{AX}$ forward: TGGAAAGGGTCAGGGAAG; $\gamma \mathrm{H} 2 \mathrm{AX}$ reverse: GACTTGTGCTGGTATCTGGGTG; Chk1 forward: AGCGCTTGGTCAAAAGGATG; Chk1 reverse: AAGCCGGAAGTCAACCAGTA; GAPDH forward: GGCACAGTCAAGGCTGAGAATG; GAPDH reverse: ATGGTGGTGAAGACGCCAGTA.

\section{Western blot analysis}

Total proteins were extracted using the ProteoPrep Total Extraction Sample Kit (Sigma-Aldrich, USA). Western blot was performed using the primary antibodies, followed by horseradish peroxidase-conjugated secondary antibodies and detection by an enhanced chemiluminescence reagent (Pierce, USA). The primary antibodies used were anti- $\gamma \mathrm{H} 2 \mathrm{AX}$, anti-Nrf2, anti-NQO-1, anti-HO-1, and anti-GAPDH from Santa Cruz Biotechnology (Santa Cruz, USA), anti-caspase-3 and anti-Chk1 from Cell Signaling Technology (CST, USA), and anti-caspase- 8 and anti-caspase- 9 from Becton Dickson (BD, USA). Secondary antibodies were from Cell Signaling Technology (CST, USA).

\section{Comet assay}

The comet assay was carried out following protocols as described previously [32]. Firstly, the slides were coated with $1 \%$ normal melting point agarose (Sangon, China). Then, cells were raised in $0.5 \%$ low melting point (LMP) agarose (Sangon, China) before being placed on the prepared slides and stored in the freezer for 5 min after being covered by coverslips. Then the cell suspensions on the slides were treated as above. Following the treatments, slides were covered with a third layer of $0.5 \%$ LMP agarose and kept in the freezer for $5 \mathrm{~min}$ again. After removing the coverslip, the slides were soaped in cold lysing buffer at $4^{\circ} \mathrm{C}$ overnight. The next day, before electrophoresis, they were flooded with cold fresh electrophoresis buffer for 30 min to allow DNA to denature. Finally, the slides were stained with ethidium bromide.

\section{Statistical analysis}

GraphPad software was used for all analyses by one-way ANOVA or $t$-test for comparison of differences between groups. $P<0.05$ indicated statistical significance. Data were presented as the mean \pm standard deviation (S.D).

\section{Results}

LBP depressed the $\mathrm{H}_{2} \mathrm{O}_{2}$-induced oxidative stress in rat chondrocytes

The chondrogenic phenotype of the purchased rat cells was first confirmed (Figures 1 A, B). Then, it was observed that the cell viability was inhibited by $\mathrm{H}_{2} \mathrm{O}_{2}$ in a dose-dependent manner (Figure $1 \mathrm{C}$ ). The optimal dose of $\mathrm{H}_{2} \mathrm{O}_{2}$ was adopted at a concentration of $0.3 \mathrm{mM}$ for the subsequent experiments. Moreover, according to the previous investigations, LBP play multiple roles in biological processes. The results showed that ROS levels were decreased substantially in LBP treatment groups using flow cytometric analysis (Figures $1 \mathrm{D}, \mathrm{E}$ ). It was suggested that LBP depressed $\mathrm{H}_{2} \mathrm{O}_{2}$-induced oxidative stress effectively in chondrocytes.

\section{LBP inhibited $\mathrm{H}_{2} \mathrm{O}_{2}$-induced DNA damage in chondrocytes}

DNA damage caused by $\mathrm{H}_{2} \mathrm{O}_{2}$ was further determined by comet assay in chondrocytes. The results showed that LBP inhibited $\mathrm{H}_{2} \mathrm{O}_{2}$-induced DNA damage compared to that of the model group (Figure $2 \mathrm{~A}$ ). Moreover, the mRNA expression of $\gamma \mathrm{H} 2 \mathrm{AX}$ and Chk1 was down-regulated in LBP treatment groups compared to that of the model group (Figure $2 \mathrm{~B}$ ). Although there was no statistical significance in $0.2 \mathrm{mg} / \mathrm{ml}$ LBP group; the expression of $\gamma \mathrm{H} 2 \mathrm{AX}$ and Chk1 was significantly decreased by $0.2 \mathrm{mg} / \mathrm{ml}$ LBP compared to model group. The 

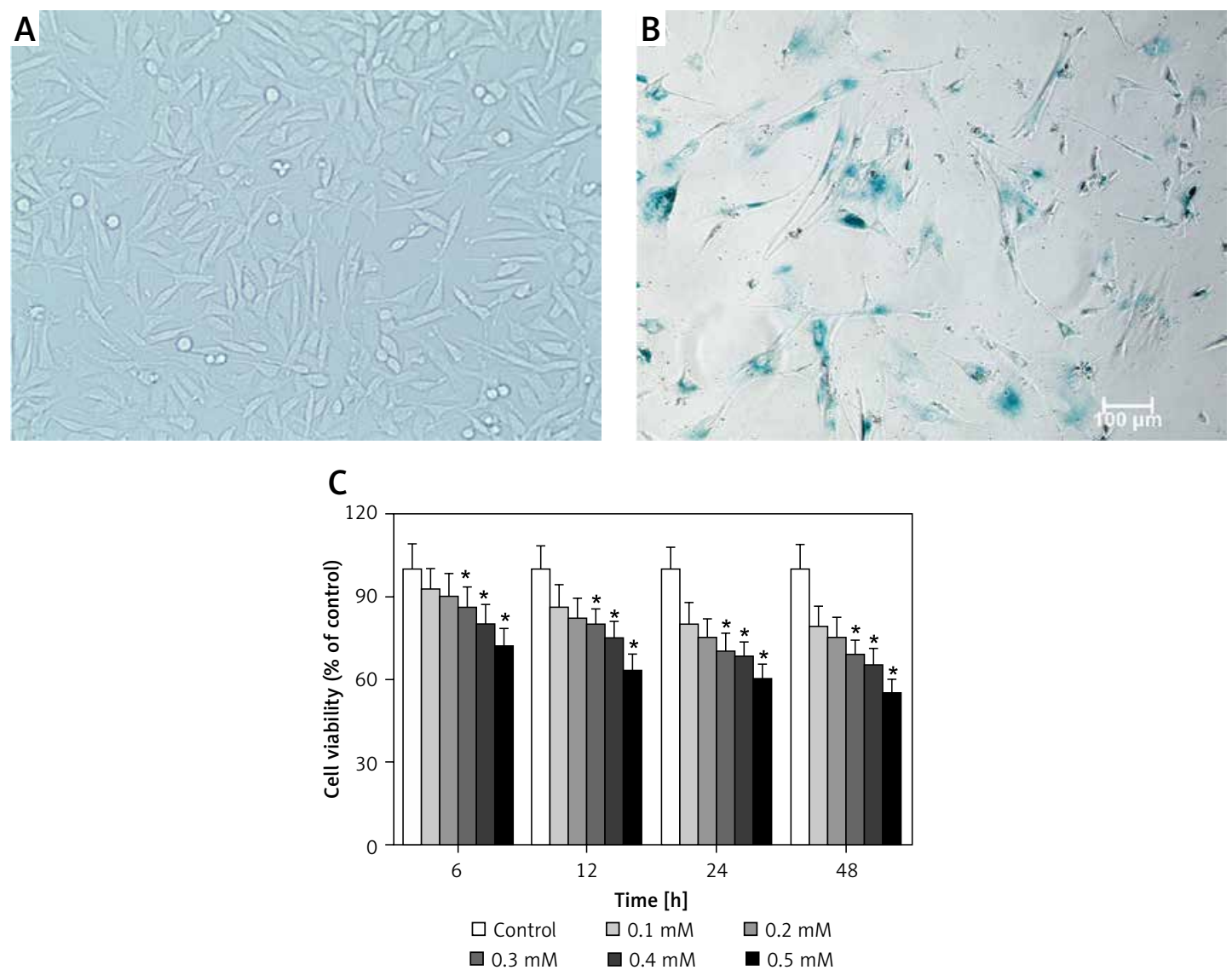

D

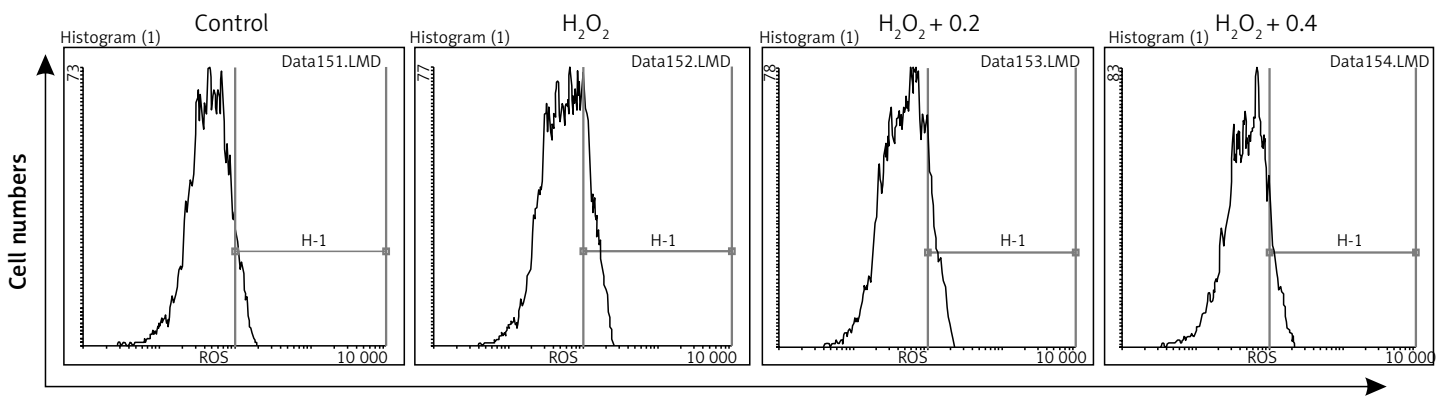

DCF fluorescence

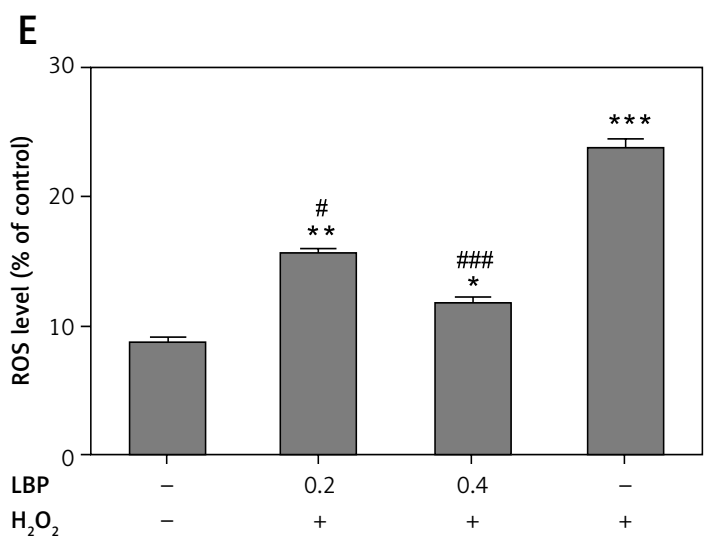

Figure 1. A, B - Identity of chondrocytes with toluidine blue staining. A - Image before staining; B - Image after toluidine blue staining. C - CCK8 assay for detection of cytotoxicity of $\mathrm{H}_{2} \mathrm{O}_{2}$. Control indicates the cells without treatment with $\mathrm{H}_{2} \mathrm{O}_{2}$; $0.1,0.2,0.3,0.4,0.5 \mathrm{mM}$ indicate the treatment concentration of $\mathrm{H}_{2} \mathrm{O}_{2} .{ }^{*} \mathrm{P}<0.05$ vs. control. D ROS measurement by flow cytometry assay. E Determination of ROS level. $\mathrm{H}_{2} \mathrm{O}_{2}\left(0.3 \mathrm{mM} \mathrm{H}_{2} \mathrm{O}_{2}\right)$; ${ }^{*} P<0.05,{ }^{* *} p<0.01$ and ${ }^{* * *} p<0.001$ vs. control; $\# p<0.05$ and $\# \# \#<0.001$ vs. $\mathrm{H}_{2} \mathrm{O}_{2}$. Control (normal cells); $\mathrm{H}_{2} \mathrm{O}_{2}\left(0.3 \mathrm{mM} \mathrm{H}_{2} \mathrm{O}_{2}\right) ; \mathrm{H}_{2} \mathrm{O}_{2}+0.2(0.2 \mathrm{mg} / \mathrm{ml}$ $\left.\mathrm{LBP}+0.3 \mathrm{mM} \mathrm{H}_{2} \mathrm{O}_{2}\right) ; \mathrm{H}_{2} \mathrm{O}_{2}+0.4(0.4 \mathrm{mg} / \mathrm{ml} \mathrm{LBP}+$ $0.3 \mathrm{mM} \mathrm{H}_{2} \mathrm{O}_{2}$ ) 
A
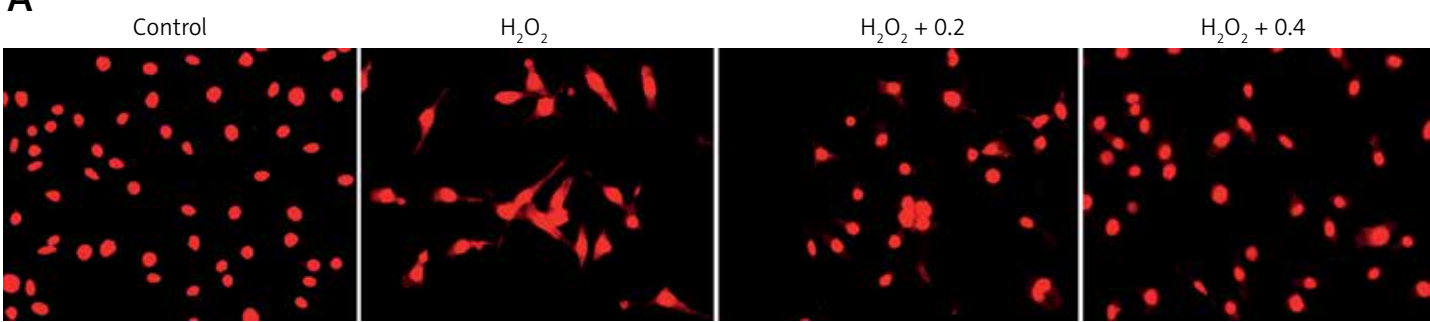

B
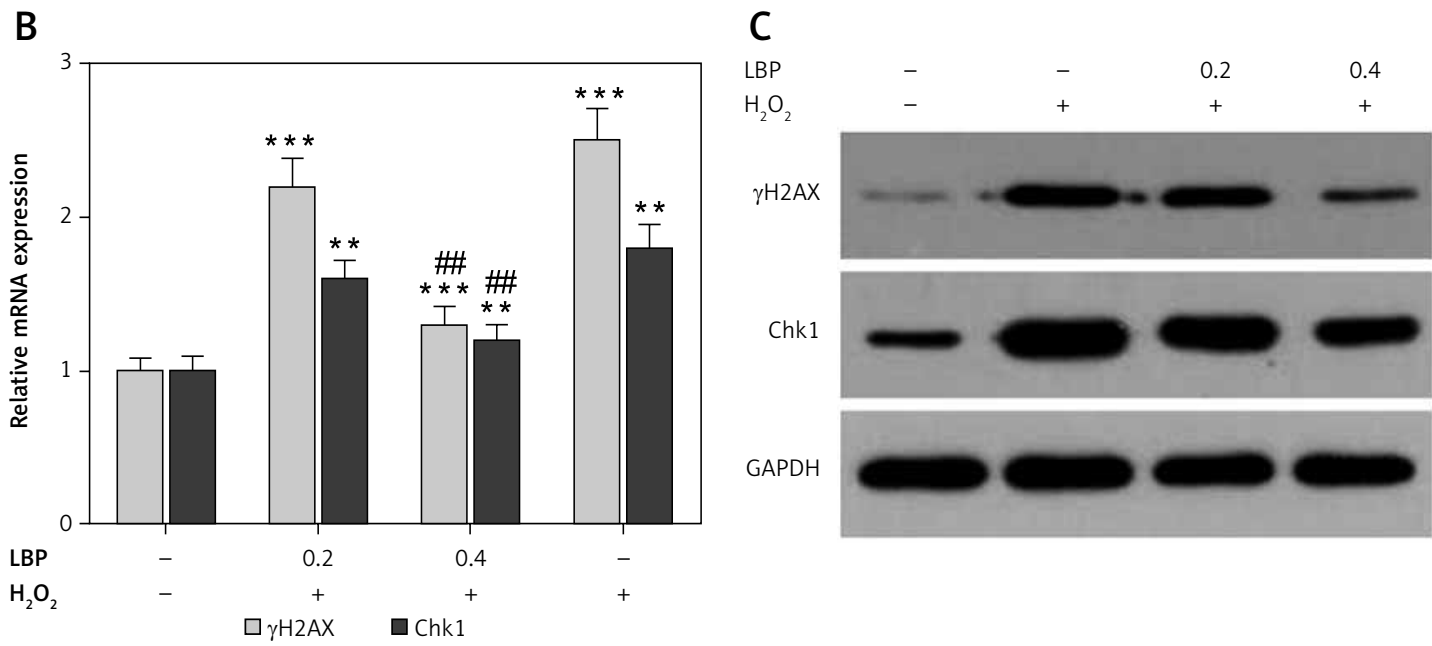

D

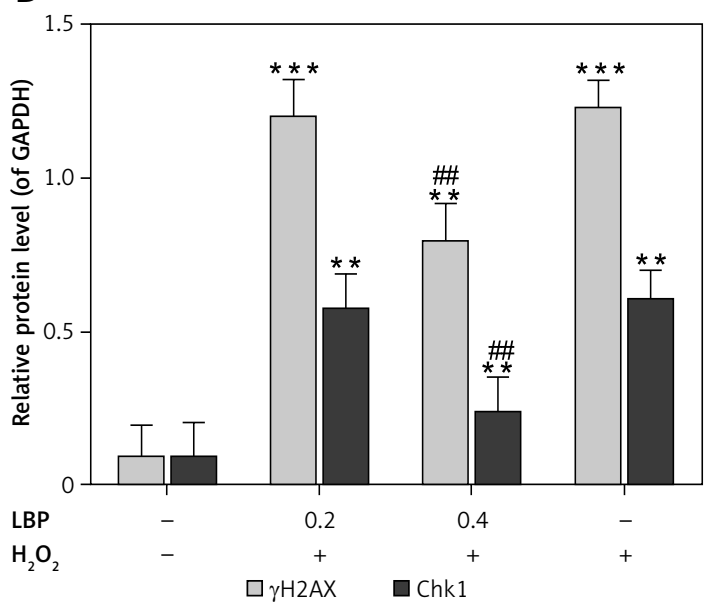

protein expression of $\gamma \mathrm{H} 2 \mathrm{AX}$ and Chk1 was significantly down-regulated in LBP treatment groups compared to that of the model group (Figures $2 \mathrm{C}, \mathrm{D})$. Therefore, LBP inhibited $\mathrm{H}_{2} \mathrm{O}_{2}$-induced DNA damage in chondrocytes.

\section{LBP decreased $\mathrm{H}_{2} \mathrm{O}_{2}$-induced cell apoptosis in chondrocytes}

Subsequently, the effect of LBP on apoptosis of chondrocytes was detected. It was noted that LBP reduced cell apoptosis compared to that of the model group (Figures $3 \mathrm{~A}, \mathrm{~B}$ ). PARP and caspase-3/8/9, apoptosis-related genes, were decreased both in the transcription and translated

Figure 2. A - DNA damage detection by comet assay. B - Quantitative analysis of $\gamma \mathrm{H} 2 \mathrm{AX}$ and Chk1. ${ }^{* *} P<0.01$ and ${ }^{* * *} p<0.001$ vs. control; $\# p<0.01$ vs. $\mathrm{H}_{2} \mathrm{O}_{2}$. C, D - Western blot analysis of $\gamma \mathrm{H} 2 \mathrm{AX}$ and Chk1. GAPDH was used as the loading control. ${ }^{* *} P<0.01$ and ${ }^{* * *} p<0.001$ vs. control; ${ }^{\# \# p<0.01}$ vs. $\mathrm{H}_{2} \mathrm{O}_{2}$. Control (normal cells); $\mathrm{H}_{2} \mathrm{O}_{2}\left(0.3 \mathrm{mM} \mathrm{H}_{2} \mathrm{O}_{2}\right)$; $\mathrm{H}_{2} \mathrm{O}_{2}+0.2\left(0.2 \mathrm{mg} / \mathrm{ml} \mathrm{LBP}+0.3 \mathrm{mM} \mathrm{H}_{2} \mathrm{O}_{2}\right) ; \mathrm{H}_{2} \mathrm{O}_{2}+$ $+0.4\left(0.4 \mathrm{mg} / \mathrm{ml} \mathrm{LBP}+0.3 \mathrm{mM} \mathrm{H}_{2} \mathrm{O}_{2}\right)$

levels in the LBP treatment groups (Figures $3 \mathrm{C}-\mathrm{E}$ ). It was found that LBP decreased $\mathrm{H}_{2} \mathrm{O}_{2}$-induced cell apoptosis effectively in chondrocytes.

\section{LBP activated Nrf2/ARE signaling in $\mathrm{H}_{2} \mathrm{O}_{2}$-stimulated chondrocytes}

To uncover the underlying mechanisms, the expression of Nrf2/ARE signaling was examined. The mRNA expression of Nrf2, HO-1 and NQO-1 was rescued significantly in $\mathrm{H}_{2} \mathrm{O}_{2}$-stimulated chondrocytes (Figure 4 A). Consistently, Nrf2, HO-1 and NQO-1 showed increased protein levels (Figures $4 \mathrm{~B}, \mathrm{C}$ ). Further, the apoptosis inhibition effect of LBP was reversed after knockdown of Nrf2 (Fig- 
A

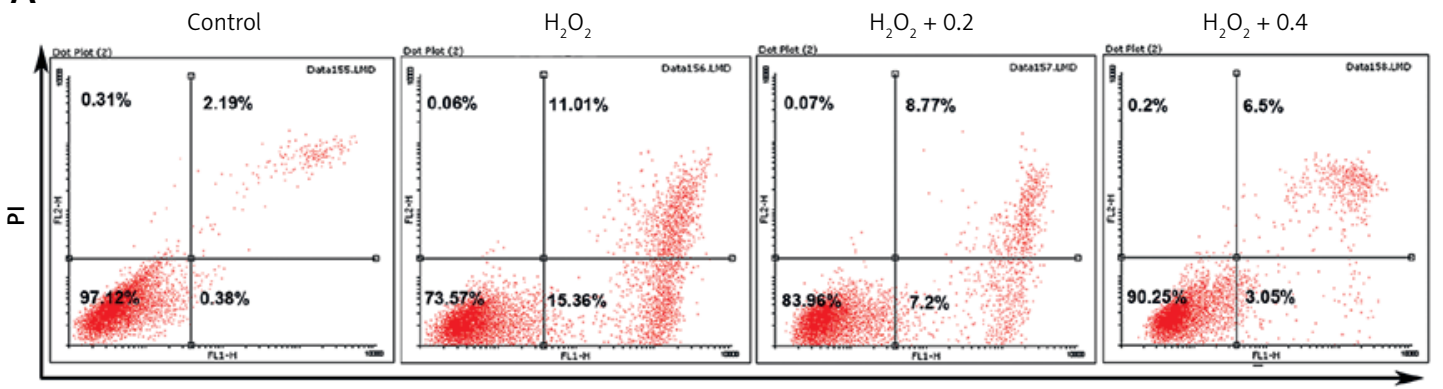

Annexin-V FITC

B

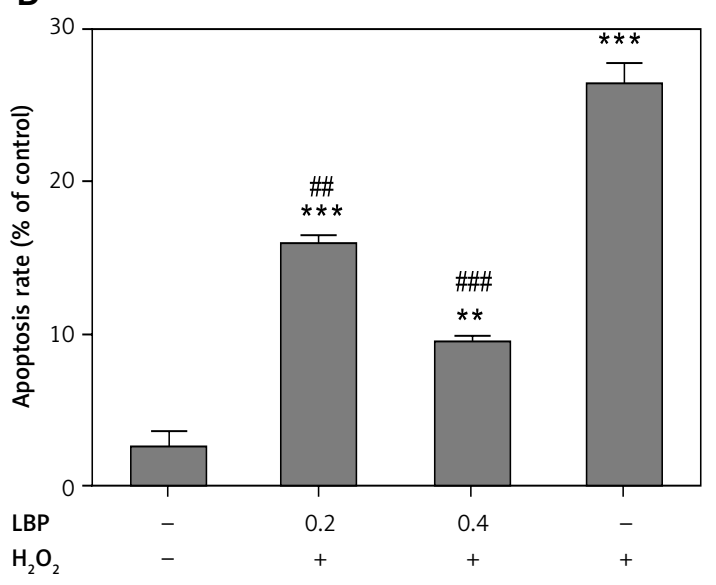

D

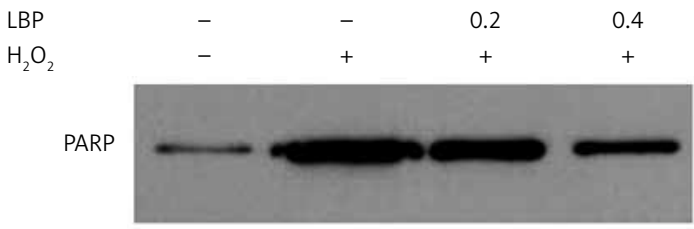

Caspase-3

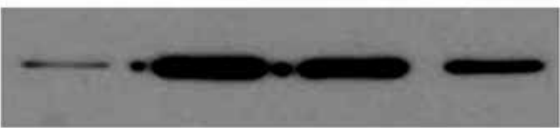

Caspase-8

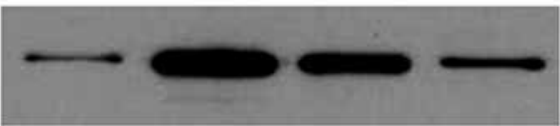

Caspase-9

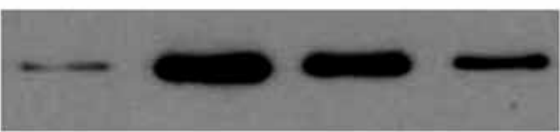

GAPDH

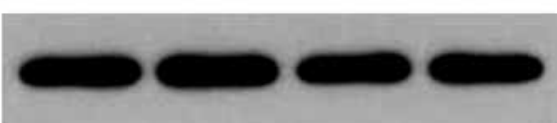

C

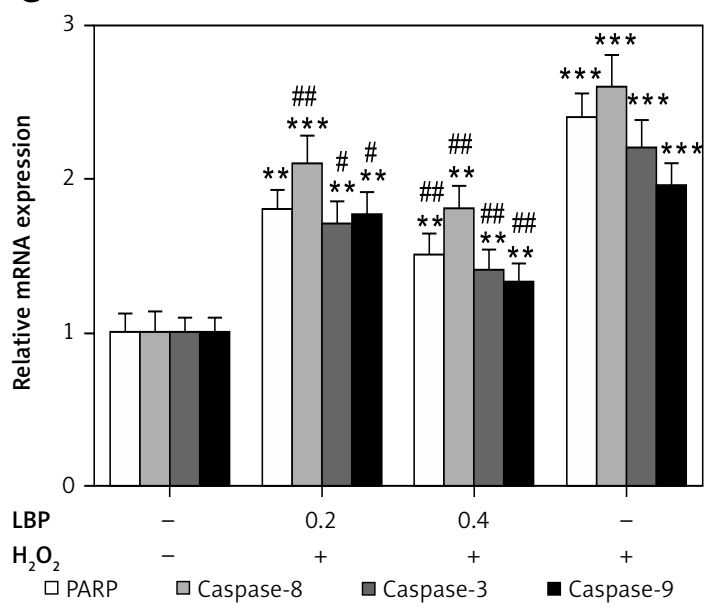

$\mathrm{E}$

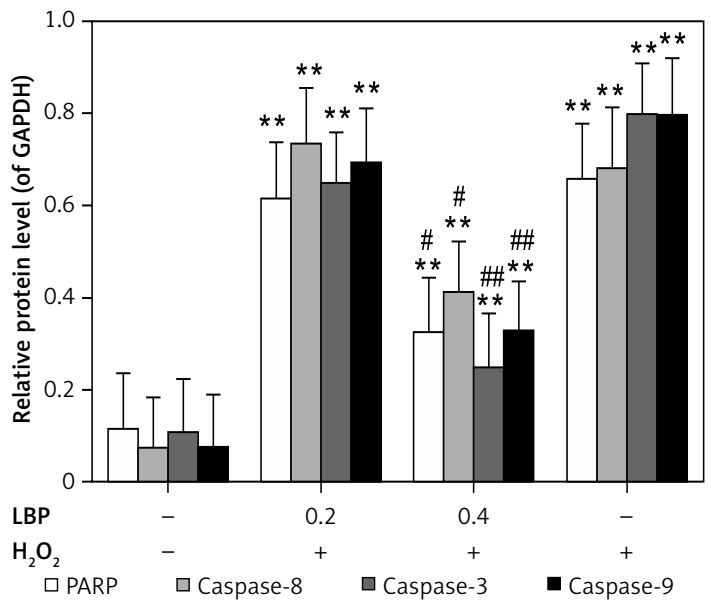

Figure 3. A - Flow cytometry analysis for apoptosis. B - Determination of apoptosis rate. ${ }^{* *} P<0.01$ and ${ }^{* * *} p<0.001$ vs. control; ${ }^{\# \#} p<0.01$ and ${ }^{\# \#} p<0.001$ vs. $\mathrm{H}_{2} \mathrm{O}_{2} . \mathrm{C}-$ Quantitative analysis of PARP and caspase-3/8/9. ${ }^{* *} P<0.01$ and ${ }^{* * *} p<0.001$ vs. control; ${ }^{*} p<0.05$ and ${ }^{\# \#} p<0.01$ vs. $\mathrm{H}_{2} \mathrm{O}, \mathrm{D}, \mathrm{E}-$ Western blot analysis of PARP and caspase-3/8/9. GAPDH was used as the loading control. ${ }^{* *} p<0.01$ vs. control; ${ }^{*} p<0.05$ and ${ }^{\# \#} p<0.01$ vs. $\mathrm{H}_{2} \mathrm{O}_{2}$ Control (normal cells); $\mathrm{H}_{2} \mathrm{O}_{2}\left(0.3 \mathrm{mM} \mathrm{H}_{2} \mathrm{O}_{2}\right) ; \mathrm{H}_{2} \mathrm{O}_{2}+0.2\left(0.2 \mathrm{mg} / \mathrm{ml} \mathrm{LBP}+0.3 \mathrm{mM} \mathrm{H} \mathrm{O}_{2}\right) ; \mathrm{H}_{2} \mathrm{O}_{2}+0.4(0.4 \mathrm{mg} / \mathrm{ml} \mathrm{LBP}$ $\left.+0.3 \mathrm{mM} \mathrm{H}_{2} \mathrm{O}_{2}\right)$ 
A

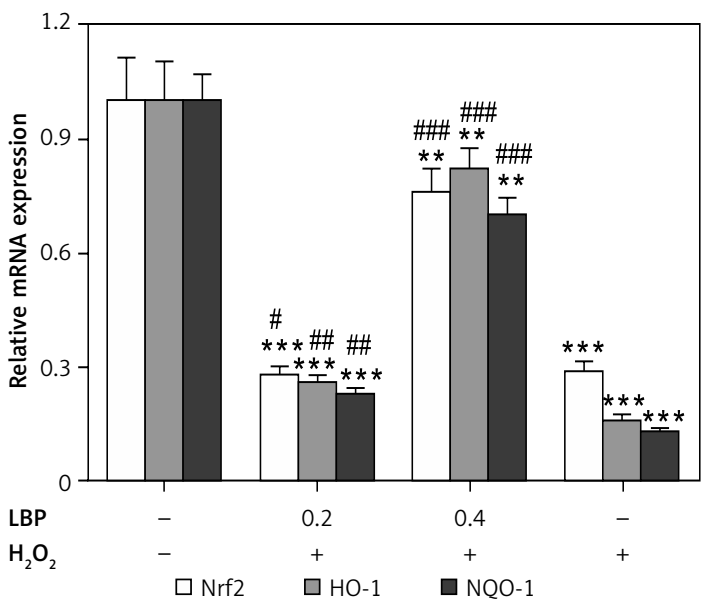

C

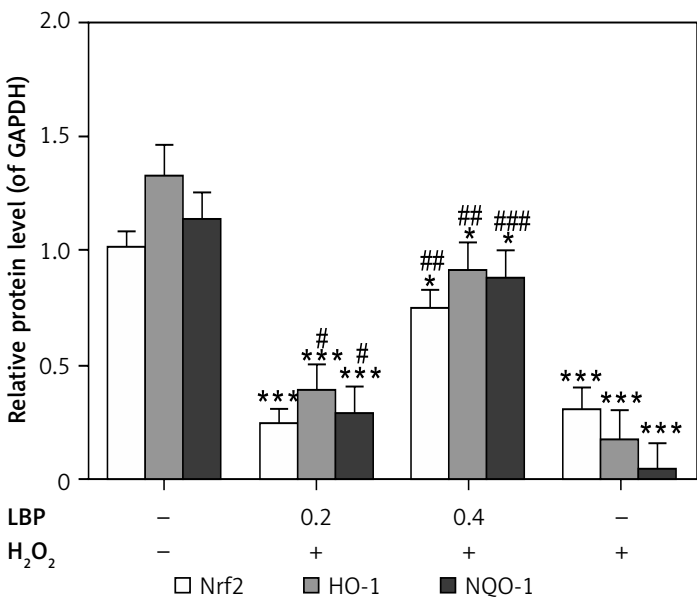

ures $5 \mathrm{~A}, \mathrm{~B})$. The mRNA and protein expression levels of Nrf2 were down-regulated after siRNA-Nrf2 transfection (Figures $5 \mathrm{C}-\mathrm{E}$ ). Moreover, the depletion of Nrf2 induced more serious DNA damage than that of the negative control group (Figures $5 \mathrm{~F}$ ). Taken together, these results indicated that pretreatment of LBP up-regulated the expression levels of Nrf2, $\mathrm{HO}-1$ and NQO-1 in chondrocytes following $\mathrm{H}_{2} \mathrm{O}_{2}$ stimulation in vitro.

\section{Discussion}

In the present study, cell viability was suppressed in $\mathrm{H}_{2} \mathrm{O}_{2}$-stimulated chondrocytes in a dose-dependent manner (Figure 1 C). Recently, oxidative stress is considered as major cause of OA pathogenesis [26], which is mainly attributed to the imbalance of redox hemostasis between ROS generation and its removal by antioxidant enzymes [33-37]. LBP is reported to facilitate the alleviation of oxidative stress. Therefore, LBP may be helpful to prevent the cytotoxicity caused by $\mathrm{H}_{2} \mathrm{O}_{2}$ in chondrocytes. Interestingly, the pretreatment of LBP in chondrocytes inhibited $\mathrm{H}_{2} \mathrm{O}_{2}$-induced ROS (Figures 1 D, E). Moreover, ROS overload would

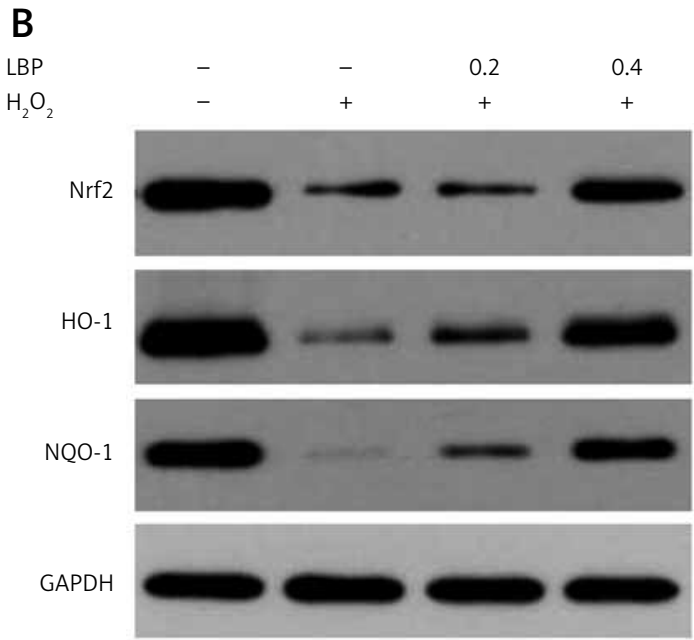

Figure 4. A - Quantitative analysis of Nrf2, HO-1 and NQO-1. ${ }^{* *} P<0.01$ and ${ }^{* * *} p<0.001$ vs. control; ${ }^{\#} p<0.05$, $\# p<0.01$ and ${ }^{\# \#} p<0.001$ vs. $\mathrm{H}_{2} \mathrm{O}_{2}$. $\mathrm{B}, \mathrm{C}-$ Western blot analysis of $\mathrm{Nrf2}, \mathrm{HO}-1$ and NQO-1. GAPDH was detected as the control of sample loading. ${ }^{\star} P<0.05$ and ${ }^{* * *} p<0.001$ vs. control; $" p<0.05, " \# p<0.01$ and ${ }^{\# \#} p<0.001$ vs. $\mathrm{H}_{2} \mathrm{O}_{2}$. Control (normal cells); $\mathrm{H}_{2} \mathrm{O}_{2}\left(0.3 \mathrm{mM} \mathrm{H}_{2} \mathrm{O}_{2}\right) ; \mathrm{H}_{2} \mathrm{O}_{2}$ $+0.2\left(0.2 \mathrm{mg} / \mathrm{ml} \mathrm{LBP}+0.3 \mathrm{mM} \mathrm{H}_{2} \mathrm{O}_{2}\right) ; \mathrm{H}_{2} \mathrm{O}_{2}+0.4$ $\left(0.4 \mathrm{mg} / \mathrm{ml} \mathrm{LBP}+0.3 \mathrm{mM} \mathrm{H}_{2} \mathrm{O}_{2}\right)$

trigger widespread DNA damage in chondrocytes [26]. In line with this report, the $\mathrm{H}_{2} \mathrm{O}_{2}$ treatment significantly evoked DNA damage, whereas the pretreatment of LBP mitigated the injury in this study (Figure $2 \mathrm{~A}$ ). In addition, it is widely recognized that $\gamma \mathrm{H} 2 \mathrm{AX}$ and Chk1 are crucial for cell cycle transition in response to DNA damage [38, 39]. The results indicated that the expression of $\gamma \mathrm{H} 2 \mathrm{AX}$ and Chk1 was down-regulated in LBP treatment groups compared to that of the model group (Figures 2 B-D). In the meantime, apoptosis generally ensues following DNA damage [33], and the oxidative stress is considered as a high risk factor for it [40]. Thus, apoptosis was further detected in this study. The results revealed that the pretreatment with LBP reduced cell apoptosis caused by $\mathrm{H}_{2} \mathrm{O}_{2}$ (Figures $3 \mathrm{~A}, \mathrm{~B}$ ). PARP and caspase-3/8/9, apoptosis-related genes [41, 42], were inhibited significantly both in the transcription and translation levels in LBP pretreatment groups (Figures 3 C $-E)$. A recent report in mice bone marrow mononuclear cells supported the apoptosis inhibition effect of LBP [43]. On the other hand, another study showed that LBP inhibited the proliferation 
A

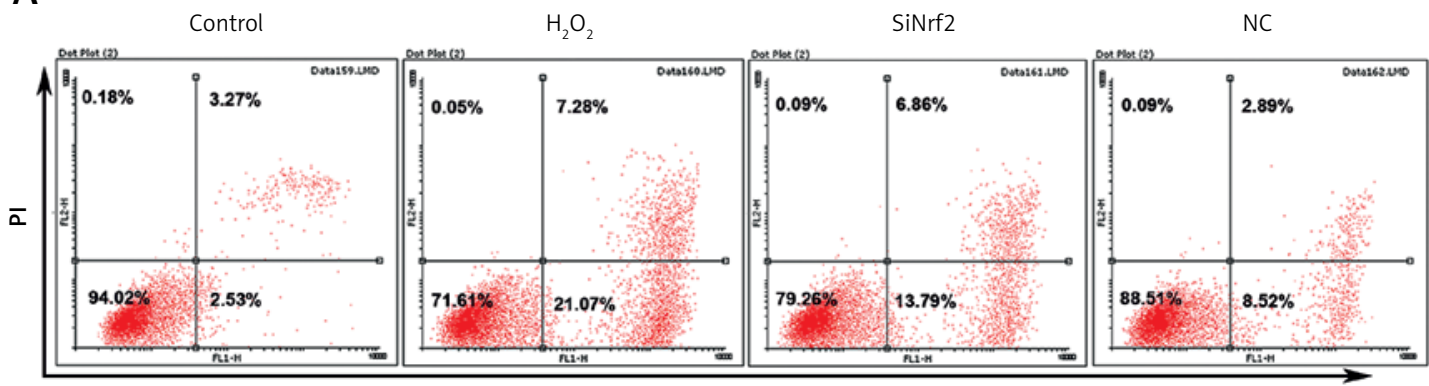

Annexin-V FITC

B

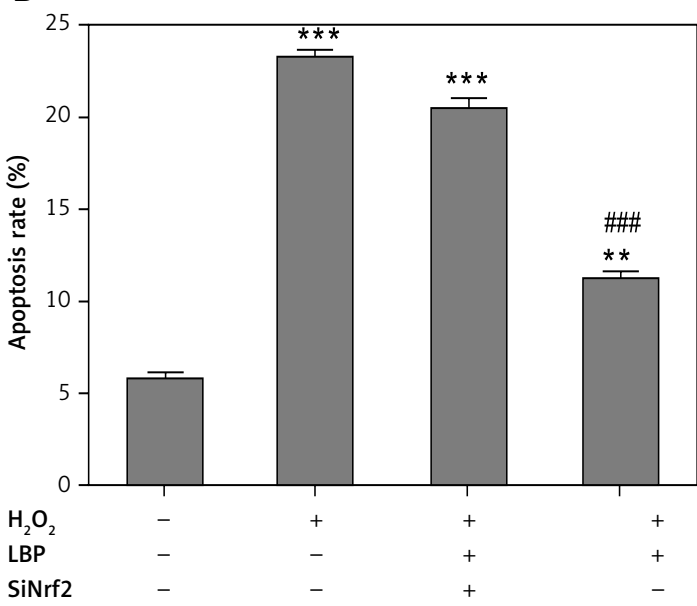

D

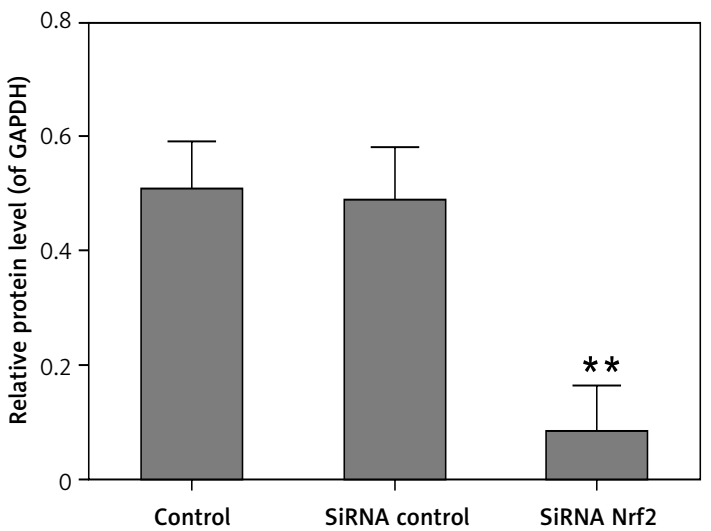

F

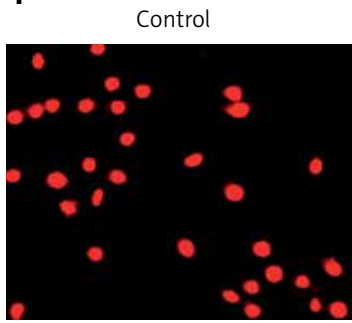

C

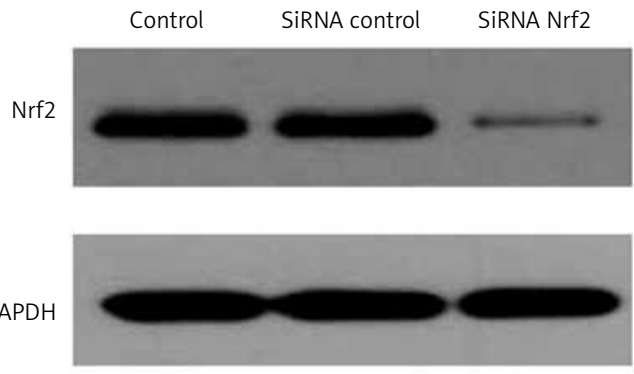

E

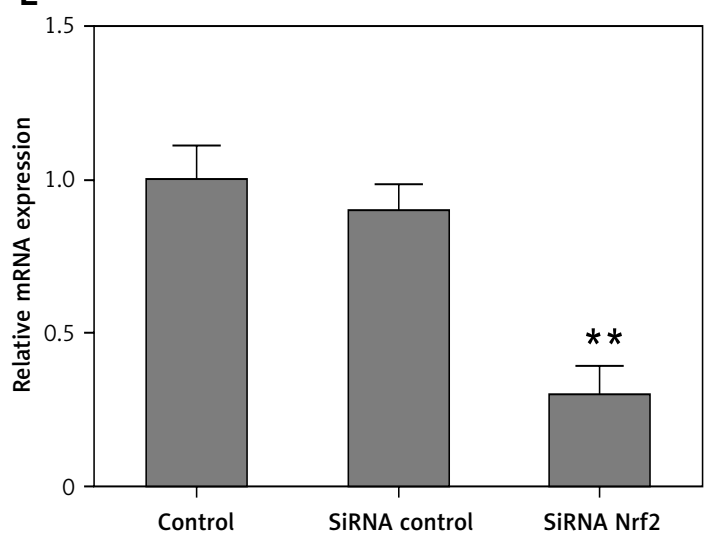

Figure 5. A - Flow cytometry analysis for apoptosis. B - Determination of apoptosis rate. ${ }^{* *} P<0.01$ and ${ }^{* * *} p<0.001$ vs. control; \#\#\# $p<0.001$ vs. $\mathrm{H}_{2} \mathrm{O}$. C, D - Western blot assay for the effectiveness of SiNrf2. GAPDH was used as the loading control. ${ }^{* *} P<0.01$ vs. control. E - Quantitative analysis for the effectiveness of SiNrf2. ${ }^{*} P<0.01$ vs. control. $\mathrm{F}-$ Comet assay for DNA damage. Control (normal cells); $\mathrm{H}_{2} \mathrm{O}_{2}\left(0.3 \mathrm{mM} \mathrm{H} \mathrm{O}_{2}\right) ; \mathrm{SiNrf2}(0.4 \mathrm{mg} /$ $\left.\mathrm{ml} \mathrm{LBP}+\mathrm{SiNrf2}+0.3 \mathrm{mM} \mathrm{H}_{2} \mathrm{O}_{2}\right) ; \mathrm{NC}\left(0.4 \mathrm{mg} / \mathrm{ml} \mathrm{LBP}+\right.$ Sicontrol + $\left.0.3 \mathrm{mM} \mathrm{H}_{2} \mathrm{O}_{2}\right)$ 
by inducing apoptosis in HeLa cells [43]. These conflicting results may be attributed to the different study model, such as different cell types and distinct concentrations of LBP adopted in these study schedules. Collectively, these results indicated that LBP protected chondrocytes by suppressing ROS generation, DNA damage and apoptosis.

Nrf2, as a redox sensitive transcription factor, is implicated play a role in oxidative stress and various inflammation reactions. Therefore, it is presumable that Nrf2 may be associated with the protective effect of LBP. Excitingly, the pretreatment of LBP rescued the expression of Nrf2 and its downstream targets such as NQO-1 and $\mathrm{HO}-1$, compared to the model group (Figures $4 \mathrm{~A}-\mathrm{C}$ ). More importantly, it was noted that the apoptosis inhibition effect of LBP was reversed obviously by the Nrf2 depletion (Figures $5 \mathrm{~A}, \mathrm{~B}$ ). In addition, DNA damage was still severe in the Nrf2 knockdown group, compared to the control (Figure $5 \mathrm{~F}$ ). It was consistent with a previous report that activation of the Nrf2 signaling pathway mitigated injury and promoted proliferation in neural stem cells in vivo following reoxygenation [44]. Taken together, it can be concluded that LBP likely exerted its antioxidative and protective effects through activating the Nrf2 signaling pathway.

However, there were limitations in the current study. Firstly, the existing research indicats that Nrf2 was modulated by multiple upstream molecules including Keap1 [45], the kinase ERK1/2 [46] and PI3K/AKT/GSK3 $\beta$ signaling $[47,48]$. Nevertheless, which upstream regulators regulate Nrf2-mediated chondroprotection, and how, were still not clear in the present study model. Secondly, the results of this study were all from in vitro data, so further investigation in vivo is still needed. Another limitation of the present study was that the chondroprotection effect may not only contribute to LBP absorption. Possibly, it may have relations with the generation of metabolites of LBP due to modification such as sulfation [49] and selenylation [50]. Therefore, the chondroprotective effects of LBP could be ascribed to the accumulative effects themselves and their metabolites. Collectively, the current study provided evidence that LBP protected chondrocytes against $\mathrm{H}_{2} \mathrm{O}_{2}$-mediated DNA damage and apoptosis through activating the Nrf2 signaling pathway.

In conclusion, the present study illustrated that LBP inhibited the ROS production in $\mathrm{H}_{2} \mathrm{O}_{2}$-stimulated chondrocytes. Moreover, LBP inhibited DNA damage and cell apoptosis caused by $\mathrm{H}_{2} \mathrm{O}_{2}$. Most importantly, it demonstrated that LBP exerted its chondroprotective effect through activating Nrf2/ARE signaling. It also highlighted the potential of LBP as a therapeutic agent and Nrf2 as a promising candidate as novel therapies for the clinical options of osteoarthritis.

\section{Acknowledgments}

Supported by Health Department of Zhejiang Province, China (No. 2017KY011 and 2017KY017), and also funded by Science and Technology Department of Zhejiang Province, China (No. 2016C37123).

\section{Conflict of interest}

The authors declare no conflict of interest.

\section{References}

1. Pap T, Korb-Pap A. Cartilage damage in osteoarthritis and rheumatoid arthritis [mdash] two unequal siblings. Nat Rev Rheumatol 2015; 11: 606-15.

2. Yudoh K, Trieu N, Matsuno H, Nishioka K. Oxidative stress induces chondrocyte telomere instability and chondrocyte dysfunctions in osteoarthritis. Arthritis Res Therapy 2003; 5: 164-4.

3. Bhagat U, Das UN. Potential role of dietary lipids in the prophylaxis of some clinical conditions. Arch Med Sci 2015; 11: 807-18.

4. Kim J, Xu M, Xo R, et al. Mitochondrial DNA damage is involved in apoptosis caused by pro-inflammatory cytokines in human OA chondrocytes. Osteoarthritis Cartilage 2010; 18: 424-32.

5. Blanco FJ, Lopez-Armada MJ, Maneiro E. Mitochondrial dysfunction in osteoarthritis. Mitochondrion 2004; 4 : 715-28.

6. Uehara Y, Hirose J, Yamabe S, et al. Endoplasmic reticulum stress-induced apoptosis contributes to articular cartilage degeneration via C/EBP homologous protein. Osteoarthritis Cartilage 2014; 22: 1007-17.

7. Hosseinzadeh A, Kamrava SK, Joghataei MT, et al. Apoptosis signaling pathways in osteoarthritis and possible protective role of melatonin. J Pineal Res 2016; 61: 411-25.

8. Nguyen LT, Sharma AR, Chakraborty C, Saibaba B, Ahn ME, Lee SS. Review of prospects of biological fluid biomarkers in osteoarthritis. Int J Mol Sci 2017; 18: E601.

9. Zhou J, Pang H, Li W, et al. Effects of Lycium barbarum polysaccharides on apoptosis, cellular adhesion, and oxidative damage in bone marrow mononuclear cells of mice exposed to ionizing radiation injury. BioMed Research Int 2016; 2016: 4147879.

10. Machado GC, Maher CG, Ferreira PH, Day RO, Pinheiro $M B$, Ferreira ML. Non-steroidal anti-inflammatory drugs for spinal pain: a systematic review and metaanalysis. Ann Rheum Dis 2017; 76: 1269-78.

11. Lazzaroni M, Bianchi Porro G. Gastrointestinal sideeffects of traditional non-steroidal anti-inflammatory drugs and new formulations. Aliment Pharmacol Therap 2004; 20 Suppl 2: 48-58.

12. Akhtar N, Haqqi TM. Current nutraceuticals in the management of osteoarthritis: a review. Ther Adv Musculoskel Dis 2012; 4: 181-207.

13. Chang RC, So KF. Use of anti-aging herbal medicine, Lycium barbarum, against aging-associated diseases. What do we know so far? Cell Mol Neurobiol 2008; 28: 643-52.

14. Liu C, Liao JZ, Li PY. Traditional Chinese herbal extracts inducing autophagy as a novel approach in therapy of nonalcoholic fatty liver disease. World J Gastroenterol 2017; 23: 1964-73.

15. Cheng J, Zhou ZW, Sheng HP, et al. An evidence-based update on the pharmacological activities and possible 
molecular targets of Lycium barbarum polysaccharides. Drug Des Dev Ther 2015; 9: 33-78.

16. Dall'Olio F, Vanhooren V, Chen CC, Slagboom PE, Wuhrer M, Franceschi C. N-glycomic biomarkers of biological aging and longevity: a link with inflammaging. Ageing Res Rev 2013; 12: 685-98.

17. Tang T, He B. Treatment of d-galactose induced mouse aging with Lycium barbarum polysaccharides and its mechanism study. Afr J Tradit Complement Altern Med 2013; 10: 12-7.

18. Mao F, Xiao B, Jiang Z, Zhao J, Huang X, Guo J. Anticancer effect of Lycium barbarum polysaccharides on colon cancer cells involves G0/G1 phase arrest. Med Oncol (Northwood, London, England) 2011; 28: 121-6.

19. Takahashi T, Saikawa Y, Kitagawa Y. Gastric cancer: current status of diagnosis and treatment. Cancers 2013; 5: 48-63.

20. Luo Q, Cui X, Yan J, et al. Antagonistic effects of Lycium barbarum polysaccharides on the impaired reproductive system of male rats induced by local subchronic exposure to 60Co-gamma irradiation. Phytother Res 2011; 25: 694-701.

21. Khan IM, Gilbert SJ, Caterson B, Sandell LJ, Archer CW. Oxidative stress induces expression of osteoarthritis markers procollagen IIA and 3B3(-) in adult bovine articular cartilage. Osteoarthritis Cartilage 2008; 16 698-707.

22. Zhang X, Li Y, Cheng J, et al. Immune activities comparison of polysaccharide and polysaccharide-protein complex from Lycium barbarum L. Int J Biol Macromol 2014; 65: 441-5.

23. Lepetsos P, Papavassiliou AG. ROS/oxidative stress signaling in osteoarthritis. Biochim Biophys Acta 2016; 1862: 576-91.

24. Yu SM, Kim SJ. Withaferin A-caused production of intracellular reactive oxygen species modulates apoptosis via PI3K/Akt and JNKinase in rabbit articular chondrocytes. J Korean Med Sci 2014; 29: 1042-53.

25. Chen AF, Davies CM, De Lin M, Fermor B. Oxidative DNA damage in osteoarthritic porcine articular cartilage. J Cell Physiol 2008; 217: 828-33.

26. Davies CM, Guilak F, Weinberg JB, Fermor B. Reactive nitrogen and oxygen species in interleukin-1-mediated DNA damage associated with osteoarthritis. Osteoarthritis Cartilage 2008; 16: 624-30.

27. Ambrozova N, Ulrichova J, Galandakova A. Models for the study of skin wound healing. The role of Nrf2 and NF-kappaB. Biomed Pap Med Fac Univ Palacky Olomouc Czech Repub 2017; 161: 1-13.

28. Harman D. The biologic clock: the mitochondria? J Am Geriatr Soc 1972; 20: 145-7.

29. Cai J, Kang Z, Liu K, et al. Neuroprotective effects of hydrogen saline in neonatal hypoxia-ischemia rat model. Brain Res 2009; 1256: 129-37.

30. Fani S, Kamalidehghan B, Lo KM, et al. Anticancer activity of a monobenzyltin complex C1 against MDA-MB-231 cells through induction of apoptosis and inhibition of breast cancer stem cells. Sci Rep 2016; 6: 38992.

31. Livak KJ, Schmittgen TD. Analysis of relative gene expression data using real-time quantitative PCR and the $2^{-\Delta \Delta C T}$ method. Methods 2001; 25: 402-8.

32. Singh NP, McCoy MT, Tice RR, Schneider EL. A simple technique for quantitation of low levels of DNA damage in individual cells. Exp Cell Res 1988; 175: 184-91.

33. Roos WP, Kaina B. DNA damage-induced cell death by apoptosis. Trends Mol Med 2006; 12: 440-50.
34. Wu X, Deng G, Li M, et al. Wnt/beta-catenin signaling reduces Bacillus Calmette-Guerin-induced macrophage necrosis through a ROS-mediated PARP/AIF-dependent pathway. BMC Immunol 2015; 16: 16.

35. Parlaktas BS, Atilgan D, Gencten Y, et al. A pilot study of the association of manganese superoxide dismutase and glutathione peroxidase 1 single gene polymorphisms with prostate cancer and serum prostate specific antigen levels. Arch Med Sci 2015; 11: 994-1000.

36. Sicinska P, Bukowska B, Pajak A, et al. Decreased activity of butyrylcholinesterase in blood plasma of patients with chronic obstructive pulmonary disease. Arch Med Sci 2016; 13: 645-51.

37. Khan N, Akhtar MS, Khan BA, Braga VA, Reich A. Antiobesity, hypolipidemic, antioxidant and hepatoprotective effects of Achyranthes aspera seed saponins in high cholesterol fed albino rats. Arch Med Sci 2015; 11: 1261-71.

38. Loffler $\mathrm{H}$, Bochtler T, Fritz B, et al. DNA damage-induced accumulation of centrosomal Chk1 contributes to its checkpoint function. Cell Cycle (Georgetown, Tex) 2007; 6: 2541-8.

39. Downs JA, Lowndes NF, Jackson SP. A role for Saccharomyces cerevisiae histone H2A in DNA repair. Nature 2000; 408: 1001-4.

40. Grishko V, Xu M, Ho R, et al. Effects of hyaluronic acid on mitochondrial function and mitochondria-driven apoptosis following oxidative stress in human chondrocytes. J Biol Chem 2009; 284: 9132-9.

41. Burkle A. Poly(ADP-ribose). The most elaborate metabolite of NAD+. FEBS J 2005; 272: 4576-89.

42. Thornberry NA, Lazebnik Y. Caspases: enemies within. Science (New York, NY) 1998; 281: 1312-6.

43. Zhu CP, Zhang SH. Lycium barbarum polysaccharide inhibits the proliferation of HeLa cells by inducing apoptosis. J Sci Food Agric 2013; 93: 149-56.

44. Shen C, Cheng W, Yu P, et al. Resveratrol pretreatment attenuates injury and promotes proliferation of neural stem cells following oxygen-glucose deprivation/reoxygenation by upregulating the expression of $\mathrm{Nrf2}, \mathrm{HO}-1$ and NQO1 in vitro. Mol Med Rep 2016; 14: 3646-54.

45. Kundu JK, Surh YJ. Nrf2-Keap1 signaling as a potential target for chemoprevention of inflammation-associated carcinogenesis. Pharm Res 2010; 27: 999-1013.

46. Khan NM, Sandur SK, Checker R, Sharma D, Poduval TB, Sainis KB. Pro-oxidants ameliorate radiation-induced apoptosis through activation of the calcium-ERK1/2-Nrf2 pathway. Free Rad Biol Med 2011; 51: 115-28.

47. Jain AK, Jaiswal AK. GSK-3beta acts upstream of Fyn kinase in regulation of nuclear export and degradation of NF-E2 related factor 2. J Biol Chem 2007; 282: 16502-10.

48. Rada P, Rojo Al, Chowdhry S, McMahon M, Hayes JD, Cuadrado A. SCF/\{beta\}-TrCP promotes glycogen synthase kinase 3-dependent degradation of the Nrf2 transcription factor in a Keap1-independent manner. Mol Cell Biol 2011; 31: 1121-33.

49. Wang J, Hu Y, Wang D, et al. Sulfated modification can enhance the immune-enhancing activity of lycium barbarum polysaccharides. Cell Immunol 2010; 263: 219-23.

50. Qiu S, Chen J, Chen X, et al. Optimization of selenylation conditions for lycium barbarum polysaccharide based on antioxidant activity. Carbohydr Polym 2014; 103: 148-53. 